\title{
EL FENÓMENO JORGE YUNDA EN LA ELECCIÓN A ALCALDE DE QUITO (2019) COMPRENDIDO DESDE LA TEORÍA DEL POPULISMO
}

The phenomenon of Jorge Yunda in the election for Mayor of Quito (2019) understood through the theory of populism

\author{
EDUARDO ENRÍQUEZ ARÉVALO \\ Universidad Andina Simón Bolivar-Sede Ecuador \\ eduardofenriquez@yahoo.com
}

Resumen: Se busca mostrar la utilidad de la teoría del populismo en general y en particular para comprender la política local. Esto a través del análisis de un caso de política local en América Latina. Desde ese punto de vista se mira que Jorge Yunda logró una comprensión privilegiada de los códigos culturales de los sectores populares de la ciudad de Quito ejerciendo dotes comunicativas excepcionales y siendo dueño de un gran conglomerado de medios de comunicación. Eso le permitió llegar a ganar la elección a la alcaldía de la ciudad en 2019. La sorpresa de esa victoria muestra la volátil institucionalidad partidista local y una relacionada pobre conexión de la élite política con grandes sectores de la población de la ciudad en medio de manifestaciones clasistas y racistas en contra de Yunda. Aquello se mira a través de una narrativa analítica del ascenso social y político de Yunda.

\begin{abstract}
The article seeks to show the usefulness of the theory of populism in general and in particular for understanding local politics. That is done through an analysis of a case of local politics in Latin America. From that point of view it is argued that Jorge Yunda achieved a privileged understanding of the cultural codes of popular sectors of the city of Quito through an execution of exceptional communicational talents and being the owner of a big media conglomerate. That allowed him to win the 2019 election to Mayor of the city. The surprise of that victory showed the volatile local party institutionality and a related poor connection of that political elite with large sectors of population of the city in the middle of classist and racist manifestations against Yunda. That is seen through an analytical narrative of the social and political ascent of Yunda.
\end{abstract}

Palabras clave: Política local; Ecuador; comunicación política; populismo; Quito Key words: Local politics; Ecuador; political communication; populism; Quito 


\section{INTRODUCCIÓN}

El fenómeno del populismo latinoamericano se ha consolidado como un tema importante en las ciencias sociales de esa región, y la literatura académica sobre el populismo en general se ha expandido en forma considerable a nivel global desde comienzos de este sigloparticularmente en los 2010s. En este artículo se busca mostrar la utilidad de la teoría del populismo para entender la política democrática contemporánea más amplia a través del análisis de un caso de política local en América Latina. Además en la literatura sobre el populismo latinoamericano las expresiones de ese fenómeno a nivel de elecciones locales tienen mucho menos importancia que las de presidentes nacionales. En este estudio se quiere contribuir también al conocimiento sobre el populismo en la política local. El caso que se estudia es el de la sorpresiva victoria en las elecciones de alcalde de Quito, Ecuador de 2019 del empresario y personalidad mediática del entretenimiento Jorge Yunda.

El populismo puede ser visto como un discurso y estilo político anti-status quo que tiende a encontrar terreno más fértil en situaciones de crisis política o económica. Desde ese punto de vista se mira que Jorge Yunda logró una comprensión privilegiada de los códigos culturales de los sectores populares de la ciudad de Quito ejerciendo dotes comunicativas excepcionales y siendo dueño de un gran conglomerado de medios de comunicación, lo cual le permitió un salto exitoso a la cumbre de la política local de esa ciudad.

En la literatura sobre el populismo latinoamericano se ha impuesto recientemente el identificar a tres oleadas y tipos de populismo en la región. Populismo "clásico" que es ambiguo e indefinido ideológicamente, populismo neoliberal o de derecha y populismo de izquierda. Aquí se toma principalmente esa tipología ideológica para sugerir que Yunda puede ser comprendido como encarnando un populismo ambiguo ideológicamente y no alineado. En el artículo también se señala la llamativa similitud del éxito electoral en la elección a alcalde de Quito de Yunda a la del también conductor de radio Gustavo Herdoiza en los años 1980s, político también visto usualmente como "populista" en la literatura académica. También se nota la similitud del caso del éxito político de Yunda con el de otras personalidades más recientes del ámbito internacional provenientes de medios de comunicación y de fama en ellos como Silvio Berlusconi, Donald Trump o Beppe Grillo.

Las encuestas anticipaban que Yunda podía aspirar a un papel protagónico en la contienda electoral para alcalde de Quito del 2019. Sin embargo su victoria fue recibida con mucha sorpresa por algunos sectores de la ciudad en redes sociales. Allí se expresaron sentimientos racistas y clasistas, en medio de la incertidumbre y preocupación por la victoria de un personaje políticamente poco conocido para algunos sectores de la ciudad de clase media y alta. La victoria de Yunda, el segundo lugar también un poco sorpresivo de la candidata "correísta" (en referencia al ex presidente Rafael Correa) Luisa Maldonado, y el alto nivel de fragmentación del voto en esa elección dan cuenta de la poca institucionalidad partidista y una relacionada correspondiente pobre conexión de la élite política con grandes sectores de la población de la ciudad. Además se puede notar la multiplicidad de candidaturas de la derecha unida a la impopular y cuestionada alcaldía de centro-derecha saliente de Mauricio Rodas, la irrelevancia electoral de la izquierda no correísta con excepción de la candidatura 
del socialdemócrata Paco Moncayo, y la existencia de un campo “anti-correísta” muy vigente en ese momento. Esas circunstancias unidas dan la posibilidad de tomarlas en cuenta dentro de la oposición populismo/anti-populismo en las cuales se da una reacción a un fenómeno político outsider en medio de una situación política incierta, y un sistema partidista precario e inestable, dentro de la división de clases jerárquica del capitalismo tardío en una ciudad post-colonial como Quito.

Metodológicamente el artículo se inspira en el concepto y propuesta metodológica cualitativa del process tracing (rastreo o seguimiento de proceso) para dar cuenta de un proceso socio-político comprendido desde la teoría contemporánea del populismo. Bennett \& Checkel (2015, pág. 7) definen al process tracing como el análisis de evidencia sobre procesos, secuencias y coyunturas de eventos dentro de un caso para propósitos de desarrollar o examinar hipótesis sobre mecanismos causales que puedan explicar el caso. Para llegar a estos mecanismos causales en este artículo se recurre a la teoría sobre el populismo y a partir de esta se penetra más a fondo a causas de naturaleza institucional e histórica-estructural para explicar el caso de estudio.

Aquel análisis permite realizar los tres argumentos sobre el caso de estudio recién expuestos: Yunda es un fenómeno político anti-establishment exitoso por actuar en una situación de dispersión e incertidumbre en la política local de Quito, es un tipo de populismo latinoamericano ideológicamente ambiguo y no alineado, y en las reacciones a los resultados de la elección a alcalde del año 2019 se desplegaron formas claras de la oposición populismo/ anti-populismo en su especificidad latinoamericana. Para llegar a esos argumentos el artículo inicia con un acercamiento general a la teoría del populismo relevante al caso de estudio. De allí pasa a analizar el proceso de ascenso socio-político de Yunda hacia alcanzar la alcaldía de Quito en forma cronológica y apoyándose en la teoría del populismo. Los datos del estudio son principalmente recogidos de medios de comunicación del país y de literatura académica relacionada a este. Aquello es procesado dentro de una narrativa analítica que mira el proceso de ascenso socio-político de Jorge Yunda hacia la alcaldía de Quito

\subsection{Populismo, populismo y anti-populismo latinoamericano}

Siguiendo a Moffitt $(2018,4)$ se propone que el populismo es un tipo de discurso y estilo político que realiza una apelación al "pueblo" en contra de una élite política, socio-económica o cultural. El populismo tiende a tomar fuerza especialmente en situaciones de crisis política o económica (Stavrakakis, y otros 2017) en las cuales sus discursos y/o estilos anti-status quo cobran más sentido frente a una élite con problemas de legitimidad o credibilidad. Roberts (2017) propone que cualquier explicación para el ascenso del populismo debe inevitablemente analizar las deficiencias de los partidos en su representatividad política, para las cuales el populismo se alza como correctivo. De allí que el populismo prospere en donde los partidos del status quo entran en crisis, o al menos donde estos excluyen o ignoren a corrientes importantes de opinión en el cuerpo político. En general se lo puede mirar como apelando y atrayendo a sectores sociales medios o bajos que se sienten poco o nada representados en la configuración política actual, por lo cual llama hacia el hacer efectiva una voluntad colectiva inclusiva (Mudde \& Rovira Kaltwasser, 2017, pág. 17). 
Pero en forma más profunda y general en relación a la política democrática contemporánea para Laclau (2004, pág. 33) el populismo es un discurso que simplifica el espacio político por medio de remplazar una serie compleja de diferencias y determinaciones por una "cruda" dicotomía con dos polos necesariamente "imprecisos". En tanto ese autor (2004, pág. 213) propone que la lógica de simplificación e imprecisión sería "la condición misma de la acción política" y de la articulación en democracia como de la de un "pueblo". Esto debido a que en política democrática se buscaría articular varias particularidades en forma efectiva en la esfera pública, dentro de una situación en la cual "ninguna racionalidad a priori lleva a esas demandas a unirse en torno a un centro" y además dentro de la existencia de elementos afectivos en la cementación de esta articulación.

En tanto estilo político, se propone aquí seguir la teoría "socio-cultural" del populismo de Pierre Ostiguy (2017) quien mira que este fenómeno alude a formas que llama "bajas" en tanto más "crudas", personalistas, culturalmente nativistas, menos sublimadas, y más transgresoras. Desde ese punto de vista el populismo así suele oponerse a y/o encontrar oposición desde sectores del establishment político o social que prefieren a lo que miran como "alto" o "bien comportado", cualificado, cosmopolita, y acorde con los procedimientos legales e institucionales. Sobre la distinción entre lo local/cosmopolita que realiza Ostiguy allí se puede mirar que los estilos o discursos populistas suelen buscar demostrar o demuestran pertenencia a una localidad a través de formas y rasgos culturales propias de esta desplegados en público. Esto en oposición a formas menos localizadas y más cosmopolitas de comportamiento o presentación pública.

La literatura global sobre el fenómeno del populismo ha crecido en forma importante desde fines de los 2000 y sobre todo desde los 2010. Tomando en cuenta aquello se puede mirar más específicamente a la muy grande literatura sobre el populismo latinoamericano, la cual se despliega y se implanta decididamente en las ciencias sociales de y sobre la región en las 3 últimas décadas del siglo XX. A través de la historia de esta se puede notar la identificación de 3 oleadas o eras históricas de fenómenos populistas en la región, y la tendencia contemporánea a identificarlos también como 3 tipos ideológicos de populismo latinoamericano (Mudde \& Rovira Kaltwasser, 2017, págs. 27-32) (Barr, 2017, págs. 10-18). La literatura temprana sobre el populismo latinoamericano (Germani, 1973) (di Tella, 1973) empezó analizando a lo que se ha llamado el populismo "clásico" de mediados del siglo XX en torno a líderes y movimientos como Juan Domingo Perón en Argentina, Getulio Vargas en Brasil, el APRA en Perú, en el Ecuador a José María Velasco Ibarra, entre otros. Sobre esos liderazgos y movimientos populistas se ha notado serias dificultades de ubicarlos ideológicamente debido a su equidistancia en el conflicto geopolítico de la Guerra Fría entre EEUU (capitalismo y liberalismo) y la URSS (comunismo). En los años 1990s se comenzó a notar una particular combinación entre liderazgos populistas y políticas neoliberales en lo que se llamó "populismo neoliberal" o incluso populismo de derecha (Roberts, 1995) (Weyland, 1999). A partir de la elección de Hugo Chávez en el año 1998 se miró la aparición de presidentes "populistas de izquierda" (Weyland, 2013) (Stavrakakis, Kioupkiolis, Katsambekis, Nikisianis, \& Siomos, 2016) dentro de la más amplia oleada de gobiernos "progresistas" o de izquierda de los 2000-2010. Para los propósitos de este artículo se procede a notar que el populismo "clásico" se caracterizaba 
por un posicionamiento que no podía ser fácilmente ubicado en el eje izquierda/derecha. Se ha notado que dicho tipo de populismo defendía consignas nacionalistas, al mismo tiempo que posiciones de inclusión de las clases medias y bajas, y de las diversas etnias dentro de una noción amplia de mestizaje.

Para cerrar esta sección nos enfocaremos en el anti-populismo y su particularidad en América Latina. Si el populismo es un discurso y estilo político anti-elitista y antiestablishment, lógicamente se puede esperar que el "anti-populismo" (Moffitt, 2018) (Stavrakakis, Katsambekis, Kioupkiolis, Nikisianis, \& Siomos, 2017) (Van Dyck, 2019) sea en mucho una autodefensa de esa élite y de ese establishment. Sin embargo, no se debería mirar a cualquier crítica ligera o puntual sobre un aspecto o acción de un gobierno o movimiento populista como "anti-populista". Siguiendo a Mouffe (2000, pp. 101-102), en un conflicto político "agonista" alguien tiene "adversarios" mientras que en uno "antagonista" uno tiene un "enemigo a destruir". En tanto el anti-populismo radica en un posicionamiento más global y antagonista a un gobierno, liderazgo o movimiento identificado como populista. Así Stavrakakis, Katsambekis, y otros (2017, págs. 10-12) parten del antagonismo y la tendencia polarizadora del discurso populista para ubicar su contraparte (el anti-populismo) que constituye el otro lado dentro de dicha "coreografía antagonista". Este es el eje de conflicto "populismo/anti-populismo" en el cual el lado anti-populista es aquel que describe a un fenómeno político peyorativamente como "populista" recurriendo a las connotaciones negativas "históricamente sedimentadas" que asocian al populismo con irresponsabilidad, demagogia, no idoneidad o tendencias anti-democráticas. En América Latina el antipopulismo ha llegado a recurrir al golpe de estado además de otras formas radicales de oposición política a un gobierno populista como se puede observar en las formas de salida del poder de presidentes populistas como Juan Domingo Perón, Joao Goulart en Brasil, o en el Ecuador de José María Velasco Ibarra o Abdalá Bucaram, así como en los intentos de golpe de estado a presidentes populistas de izquierda como Hugo Chávez (2002) o Rafael Correa (2010).

Además en el anti-populismo latinoamericano se ha reportado motivaciones clasistas y racistas actuando en los campos socio-políticos anti-populistas. Eso comprensible si se mira que en América Latina en general las personas blancas y de color de piel más claro están sobre-representadas en las élites políticas, económicas y culturales, mientras las personas indígenas o afrodescendientes están sobre-representadas en los sectores poblacionales de la región más pobres y marginados (Johnson III, 2012, p. 307). En tanto podemos notar como un historiador del anti-peronismo, la forma primordial del anti-populismo argentino, caracteriza a dicho fenómeno. Nállim (2014, pp. 18-19) ve que el anti-peronismo ha tendido a mirar que las "masas" peronistas son incultas y con una fuerte tendencia hacia la violencia, al mismo tiempo que las denigra con calificativos y estereotipos clasistas y racistas. Clasismo y racismo también ha sido notado en varios otros opositores radicales de liderazgos o presidentes populistas latinoamericanos. Aquello se ha reportado contra los seguidores del caudillo colombiano Jorge Eliecer Gaitán (Braun, 1986, pp. 124-125), del presidente boliviano Evo Morales (Lucero, 2017, p. 304), del presidente Getulio Vargas en Brasil (Hentschke, 2006, p. 7) (Woodard, 2006, p. 93), y del presidente venezolano Hugo Chávez. En el caso de Chávez, un presidente con rasgos físicos mestizos y afrodescendientes, 
los calificativos racistas y clasistas han sido dirigidos por sectores del anti-chavismo también contra ese mismo presidente (Herrera Salas, 2005).

\subsection{De las tarimas a la televisión y a la alcaldía}

Jorge Yunda nació en el cantón primordialmente rural de Guano en la provincia de Chimborazo, provincia con una alta población indígena. Su infancia fue humilde según lo que reporta la revista Vistazo (2019), siendo su madre costurera y su padre zapatero en el barrio de San Roque de la ciudad de Quito en donde comenzó a vivir a los 10 años de edad. En el Colegio Franciscano "San Andrés" adquirió su vocación animalista por la que se le conoce hoy como alcalde. Se graduó de Médico Cirujano en la Universidad Central del Ecuador y llega a trabajar en algunos hospitales de la ciudad, pero ya venía relacionándose con el medio de la radio. En el año de 1989 forma el grupo de rock romántico "Sahiro" que logra una considerable popularidad nacional y cierta difusión en países vecinos. Con aquello inicia en la vida de Yunda lo que Alomes y Mascitelli $(2013,31)$ miran en la celebridad como forma de poder cultural y social en la cual la fama de quien la posee puede tomar una vida en si misma que trasciende la razón original de la fama. Así desarrolló una llamativa facilidad en cambiar de oficios después de lograr considerable éxito y notoriedad en ellos.

En el año 2001 decide iniciar su famosa marca de entretenimiento "Canela" en la radio, la cual ha llegado a incluir varias frecuencias a nivel nacional en Costa, Sierra y Oriente. Allí supo combinar el ser propietario de una cadena radial en expansión con el ser conductor y animador. El público de sus radios giraba en torno a los sectores populares en forma masiva en donde combinaba música animada y chistes. Así "El taxista o el conductor de bus, junto a sus pasajeros...tienen en el Lorito-así lo tratan muchos-una válvula de escape para disfrutar por un momento de los chistes que son fruto de la propia idiosincrasia ecuatoriana." (La Historia, 2019) Así con su banda de rock romántico se acostumbró a la ovación y el reconocimiento de masas. Pero su trabajo en la radio y posterior consolidación como dueño de una cadena de radios de alcance nacional cultiva además una cercanía y comprensión socio-cultural privilegiada de una considerable masa de población de la ciudad y del país.

En este punto se puede notar la similitud de este caso con el de Silvio Berlusconi en Italia. Berlusconi es identificado como un líder populista en la literatura, y se lo ve como un caso importante de ese fenómeno en la política reciente (Alomes \& Mascitelli, 2013) (Ruzza \& Balbo, 2013). De allí que Manucci (2017, pág. 9) note algo que resalta todavía más en la similitud entre Yunda y Berlusconi al ver que este segundo habría establecido una conexión fuerte con su audiencia gracias a una habilidad comunicativa fuera de lo común agudizada durante sus años como cantante en cruceros. Aquello le posibilitó posteriormente acumular un conglomerado inmenso de medios de comunicación que le permitieron su gran éxito político posterior. Los años 2010 inician con el conglomerado radial "Canela" saltando a la televisión con Canela TV, en donde Yunda pasa también a aparecer como animador de programas que hacían algo similar a lo que hace su programa en la radio-alternar música popular con chistes. Una coincidencia más aparece entre Berlusconi, dueño del poderoso equipo AC Milán, cuando Yunda decide postularse para la presidencia del Club Deportivo 
el Nacional y gana esa posición en el año 2013. Lo que se debe resaltar en esta comparación entre dos líderes políticos de países tan distantes es principalmente la combinación exitosa entre dotes comunicacionales y astucia empresarial para acumular medios de comunicación masivos que les permiten obtener el éxito político. En forma más amplia, desde el punto de vista de los estudios más globales recientes sobre el populismo, el fenómeno Yunda puede verse como similar al éxito político de personalidades provenientes del ámbito del entretenimiento televisivo masivo como el recién mencionado Silvio Berlusconi, Donald Trump, Beppe Grillo, o Volodymyr Zelensky. Esto llega a ser más claro cuando se mira que la alcaldía de Yunda adoptó en su inició ya el slogan "Quito, grande otra vez" el cual evoca al slogan de Trump de "Make America Great Again".

Aquí ya podemos mirar los inicios en la política de Yunda. En el año 2006 gana la presidencia el candidato outsider de izquierda Rafael Correa y en ese contexto revista Vistazo (2019) mira sobre Yunda que "ese capital de fama le acercó a Rafael Correa antes de que este sea Presidente. Con el tiempo, la amistad con Correa se fue afianzando así como su cercanía con el poder político desde el 2006”. De allí Correa pasará a ser entrevistado por Yunda a menudo en el programa que conducía en su radio (El Universo, 2019). Aquello determina el que el Consejo Nacional de Radiodifusión y Televisión (CONARTEL) pase a ser presidido por Yunda hasta el año 2009, cuando Yunda es destituido por conflicto de intereses al ser al mismo tiempo concesionario de frecuencias radiales y tener un cargo público de regulación de ese tipo de actividad (El Comercio, 2009). Desde ese entonces inicia la cuestionada influencia suya en los procesos de concesión de frecuencias radiales. Según diario El Universo (2019), basado en un estudio de la ONG Fundamedios, en un modelo de negocios familiar el Grupo Canela-Yunda llegó a ser concesionaria de 50 frecuencias de radio. En octubre del 2018 la Agencia de Regulación y Control de las Telecomunicaciones (Arcotel) ordenó revertir frecuencias concesionadas a ese grupo en varias provincias por un informe de la Contraloría del Estado. Así su creciente influencia social y conexiones políticas le permiten agrandar su conglomerado mediático.

\section{IDEOLOGÍA, REPRESENTACIÓN SOCIALY POPULISMO EN LACONTIENDA POR LA ALCALDÍA}

Como se notó en la sección teórica de este artículo, los discursos y estilos populistas encuentran tierra fértil en sectores sociales de precaria o nula representación política o inclusión socio-económica, así como en situaciones de crisis política o económica. Con Roberts (1995) se miró que el populismo prospera en donde los partidos del status quo entran en crisis, o al menos donde estos excluyen o ignoren a corrientes importantes de opinión en el cuerpo político. Barr (2017: 143) señala, a través de un estudio comparativo entre 11 países latinoamericanos, que solo Perú tuvo un sistema de partidos más débil que Ecuador durante el periodo 1996-2010. Freidenberg (2014) nota que el sistema ecuatoriano es además uno de los menos nacionalizados y más regionalizados de América Latina, lo cual produce una alta incongruencia de la competencia entre el nivel nacional y local desde el regreso a la democracia, junto con una fragmentación de la oferta electoral. En relación a aquello Basabe (2016: 943) señala que las organizaciones sociales en el Ecuador se fueron debilitando en el periodo 1979-2014 y como consecuencia los partidos que las representaban se habrían visto 
afectadas en su apoyo electoral o simplemente desaparecieron. Como experimentando este proceso menciona al Partido Socialista Ecuatoriano, al MPD, a la ID y a Pachakutik a partir del 2003. Basabe en tanto relaciona aquello con el hecho de que en el país se hayan venido fortaleciendo las estrategias electorales basadas en "maquinarias electorales, caudillistas y dependientes de la figura del líder del momento".

El sistema de partidos de la política quiteña pudo tener estabilidad en su ordenamiento partidista desde fines de los 1990s hasta el año 2009. Este entra en una alta volatilidad cuando sale de la alcaldía la socialdemocracia de la Izquierda Democrática (ID) en el 2009, la cual estuvo antes precedida en la alcaldía en los 1990s principalmente por el partido demócrata cristiano Democracia Popular (DP). En el año 2009 gana la alcaldía Augusto Barrera del movimiento Alianza País (AP) del presidente Rafael Correamovimiento electoral usualmente caracterizado como "populista" (De la Torre, 2013) y “populista de izquierda” (Mudde \& Rovira Kaltwasser, 2017, pág. 31) (Barr, 2017, pág. 2) (Weyland, 2013)-en medio de la desaparición de la DP y de la ID. Aquello podía hacer pensar que se consolidaría una nueva hegemonía partidista debido a la fortaleza de AP bajo su líder, el presidente Rafael Correa. Sin embargo, Barrera pierde la reelección en el año 2014 frente a un joven candidato, Mauricio Rodas, quien lideraba un movimiento electoral de centro-derecha liberal de reciente formación. Rodas termina su alcaldía con un índice de aceptación de apenas 28,95\% (Confirmado.net, 2019) y decide no perseguir su reelección en las elecciones del 2019. Aquello puede también haber determinado la alta fragmentación de la oferta electoral de la derecha en esa elección debido a que se perdió al candidato natural de esta, el candidato alcalde en funciones Rodas en búsqueda de la reelección. Así la inestabilidad y poca previsibilidad ya entraron a dominar la política quiteña en el año 2009, lo cual hacia muy difícil el pronóstico para saber quién sería el próximo alcalde de la ciudad en el año 2019.

Esa incertidumbre y fragmentación de la política quiteña era aumentada por la crisis en el partido de gobierno AP debido a la división interna del año 2018 de la cual emergieron dos facciones identificadas como "morenista" (AP) (alineada al presidente Lenin Moreno) y "correísta" (alineada con el ex presidente Rafael Correa). Se puede retomar el análisis del proceso de ascenso político de Yunda aquí debido a que él es electo por AP como Asambleísta por Pichincha en 2017. Frente a la división de AP se reporta que Yunda miro allí "que se sentía como cuando los padres se divorcian y el niño no sabe "si irse con el papá o la mamá"” (El Universo, 2019). Para mediados del 2018 ya se rumoraba que Yunda se postularía a la alcaldía de Quito, y se confirmó el que no optaría por alguna de las dos facciones de AP recién mencionadas cuando finalmente se inscribió a esa contienda por el pequeño movimiento Unión Ecuatoriana (UE).

UE fue fundado por el ex Fiscal General Washington Pesantez "quien dice que Yunda se le acercó y le planteó ser candidato, que este no "estuvo contaminado" por el correísmo y que es una persona representativa de sectores populares que nunca gobiernan y que han permanecido postergados" (El Universo, 2019). Esta cita da cuenta de la visión personal sobre sí mismo y/o de la imagen que Yunda quería proyectar políticamente en la contienda para alcalde. Así Yunda quería ser visto como 
un candidato con fuertes raíces en los sectores populares de la ciudad, y no proveniente de las élites históricas de esta, aunque lo hacía en forma poco clara en torno a adhesión ideológica o programática.

En la campaña electoral anunciaba que buscaba solucionar los problemas de movilidad, basura, seguridad y empleo de la ciudad en tanto "Son problemas solucionables y solo se necesita de liderazgo y una gestión diferente a lo que se viene haciendo" (El Universo, 2019). Algunas teorías y visiones sobre el populismo suelen enfatizar la adhesión o promoción a discursos polarizantes o antagonistas, pero en el caso de Yunda se puede sugerir que su populismo es mas de estilo y de liderazgo personalista outsider que de discurso antagonista. De allí que decía que "no todo está mal, que no va a refundar la ciudad y tampoco irá a buscar la descalificación de nadie" (El Universo, 2019). En la red social Twitter hasta agosto del 2019 se presenta como "Ecuatoriano, Alcalde de Quito, médico de profesión, comunicador con pasión, hincha de El Nacional, animalista y político sin mañas." Así se presenta como "ecuatoriano" y es hincha del equipo de futbol "El Nacional" lo cual evoca en cierta forma al nacionalismo que no se alineaba ideológicamente del populismo "clásico" de mitad del siglo XX. En tanto se propone en este artículo que Yunda, tipológicamente en el populismo latinoamericano, puede ser ubicado como un populismo "ambiguo" e indefinido ideológicamente. Aquello se confirmó cuando Yunda gana la elección a alcalde del 2019 y entre sus colaboradores cercanos podía tener tanto a Santiago Guarderas (ex Director provincial del derechista Partido Social Cristiano) como primer vicealcalde y a Pablo Dávalos (conocido economista de izquierda y candidato a alcalde en esa elección por el partido indigenista de izquierda Pachakutik).

La peculiaridad del populismo ambiguo o indefinible ideológicamente de Yunda, que proviene de popularidad obtenida en los medios de comunicación masivos, sin embargo no es nueva en la historia democrática de la ciudad. Antes de que inicie el bipartidismo entre DP e ID en la política quiteña a fines de los 1980 s, un muy popular locutor de radio llamado Gustavo Herdoiza decidió utilizar ese reconocimiento y admiración masiva para entrar a la carrera por la alcaldía de la ciudad y ganarla en el año 1984. Herdoiza fue así alcalde de Quito entre 1984 y 1988 y también era un "chagra"-apelativo quiteño para denotar a alguien nacido fuera de la ciudad-nacido en la ciudad de Riobamba. Ya estaba activo en la radiodifusión en la ciudad en los 1950s y, en forma similar a Yunda, llega a ser propietario de la conocida Radio Tarqui en la cual se dedicaba a la difusión y promoción de música de artistas nacionales, llegando a organizar espectáculos públicos en torno a aquello en sectores pobres de la ciudad compuestos por población de migración reciente a esta (Vásquez, 2017, págs. 14-15). Al igual que Yunda, Herdoiza utilizó una etiqueta electoral de poca claridad ideológica o programática llamada "Partido Demócrata".

Retomando parte del análisis de Basabe (2016) y del mas teórico de Roberts (2017), en tanto se puede mirar que el éxito electoral de Herdoiza y Yunda toman fuerza dentro de la creciente pérdida institucional de nexos poblacionales con organizaciones y partidos políticos que se da en el país y la ciudad, y dentro de la creciente tendencia hacia el personalismo en la oferta electoral por sobre los partidos programáticos o ideológicos, en medio de una coyuntura de crisis y dispersión de representación política local. 


\section{POPULISMO Y ANTI-POPULISMO QUITEÑOS}

Las elecciones para alcalde contaron con una alta fragmentación de la oferta electoral que produjo 18 candidatos y dio como ganador a Yunda con apenas un 21,39\%. El segundo lugar fue ocupado por la candidata del correísmo (Fuerza Compromiso Social) Luisa Maldonado con un 18,42\%. El tercero por el candidato de la ID Paco Moncayo con un 17,78\% y el cuarto lugar por el candidato de centro derecha liberal Cesar Montufar (Movimiento Concertación) con un 16,93\%. En un estudio de genero sobre la elección a alcalde del 1984 se mira que Herdoiza se convirtió en una especie de "interlocutor de los sectores populares" (Rojo, y otros, 1984, pág. 22). En ese documento también se reporta una encuesta sobre razones de su apoyo electoral donde se reiteran "pueblo", "pobre" y "marginados" y como "atributo del líder" y los términos el término "pueblo-pobre", "porque es un hombre del pueblo"” y "es como nosotros" asociados a Herdoiza. En un estudio sobre las elecciones para alcalde del 2019 Unda (2019) mira algo similar en tanto auto-identificación y subjetividad política expresada electoralmente de sectores populares. A través de un análisis socio-espacial, mira que el voto en esa elección estuvo fuertemente determinado por un eje "centro-periferia" entre el eje "norte-sur" de la ciudad, y dentro del sur y del norte así mismo centros y periferias visibles desde un análisis de voto por parroquias. Así Unda mira que las clases populares, tanto en el norte y en el sur, votaron por lo que llama las opciones "populistas" (Yunda y Maldonado) y en mucho la votación combinada de esas dos candidaturas serian la votación de AP “en sus mejores momentos". Unda si diferencia que el populismo de Maldonado sería un populismo más "orgánico" mientras que el de Yunda uno más "disperso". En el presente artículo se propone que la diferencia además es de una mayor claridad ideológica en el caso de Maldonado ("correísmo" y en tanto un "populismo de izquierda" siguiendo la antes mencionada literatura sobre el populismo de Correa) que la del populismo más ambiguo y poco claro ideológicamente de Yunda.

La sorpresa y preocupación por esos resultados fue determinada por las encuestas previas que tendían a mostrar una buena posición de Moncayo y la ID para ganar la alcaldía. Esto pese a que si mostraban al final el ascenso de las candidaturas de Yunda, Maldonado y Montufar. Las redes sociales como Facebook y Twitter pasaron a ser un lugar de despliegue de esas emociones, y entre estas se notaron y denunciaron expresiones racistas y clasistas en

contra de Yunda, Maldonado y sus votantes. En la literatura sobre el racismo en el Ecuador así se ha hablado de un "liberalismo del temor" (Prieto, 2004, pág. 29) dentro de las elites liberales del país “y, particularmente, sus imágenes sobre los sujetos indígenas” en coyunturas particulares donde se revela "el miedo de los grupos dominantes por la proximidad de los nativos". Esto lo propone esa autora dentro de un contexto literario en el cual "varios investigadores contemporáneos han llamado la atención sobre el miedo que la población nativa, los pobres y el cambio social provocan en las elites".

Un artículo de opinión en el diario El Telégrafo describía la sorpresa mezclada con miedos racistas y clasistas del resultado de la elección a alcalde del 2019 notando un "bochornoso racismo" por la victoria de Yunda. Ese artículo mira que:

...Se ha criticado fuertemente al alcalde electo en redes sociales, con memes ofensivos, no por su postura política, su trayectoria empresarial o profesional, sino por su fenotipo 
y su origen humilde, cual si fueran atributos cuestionables para un gobernante en un país altamente diverso en lo cultural, social y con harta mezcla genética. Empero, con una minoría elitista, también mestiza, pero que presume de "pureza y supremacía de raza". ¡A superar su tara colonial! Hay sectores que se siguen sintiendo nobles por tener cierto apellido o condición social, más allá de toda lógica democrática... (Salazar Medina, 2019)

Un profesor de la FLACSO-Sede Ecuador miraba que además aquello se presentó como "lógica clasista-elitista: no ser de las elites sociales, no ser blanco, no representar la imagen de burgomaestre aristocrático que ha tenido la ciudad" (FLACSO Radio, 2019).

Tal como se notó en la literatura sobre el populismo en la sección teórica de este artículo, los imaginarios racistas y clasistas expresados dentro del fenómeno del "antipopulismo" se han expresado desde los días del populismo clásico de mediados del siglo XX. Lo recién descrito sobre las elecciones a alcalde de Quito muestra solamente un caso más de ese tipo de expresiones manifestándose en los sectores socio-políticos que expresan un antagonismo contra los liderazgos y movimientos identificados peyorativamente como "populistas". Los imaginarios descritos en las citas que se acaba de considerar muestran visiones y aspiraciones de reafirmación de un ordenamiento jerárquico tradicional en torno a raza y clase en el liderazgo y el ejercicio del poder en la ciudad. Se mira allí la persistencia de la confluencia entre estructuras e imaginarios sociales de larga duración. Esto fruto de la historia de las luchas sociales en la ciudad a través de la colonización española y su sistema de diferenciación racial y de clase, y de una construcción estatal del Ecuador y de la ciudad de Quito en torno a ese legado colonial. Pero aquí esto aparece adaptándose a la modernidad tardía actual y su contexto tecnológico de las redes sociales del internet. Las elecciones quiteñas del 2019 muestran así el despliegue de las luchas sociales entre sectores de élite y de la subalternidad social en su especificidad latinoamericana, mediadas por la institucionalidad de la democracia de masas contemporánea y sus particularidades en Quito y Ecuador.

\section{CONCLUSIONES}

En este estudio se buscó mostrar la utilidad de la teoría del populismo para comprender la política democrática contemporánea. También se quiso contribuir a la comprensión del populismo, en tanto discurso y estilo político, en la política local. Se hizo aquello a través del análisis del caso de la sorpresiva victoria en las elecciones de alcalde de Quito Jorge Yunda en el 2019.

Se miró que el populismo es un tipo de discurso y estilo político que realiza una apelación al "pueblo" en contra de una élite política, socio-económica o cultural. Y que ese tipo de fenómenos políticos tienden a tomar fuerza especialmente en situaciones de crisis política o económica (Stavrakakis, y otros 2017) en las cuales sus discursos y/o estilos anti-status quo cobran más sentido frente a unas élites con problemas de legitimidad o credibilidad. En general se lo puede mirar como apelando y atrayendo a sectores sociales medios o bajos que se sienten poco o nada representados en la configuración política actual, por lo cual llama hacia el hacer efectiva una voluntad colectiva inclusiva (Mudde y Rovira Kaltwasser 2017, 17).

Yunda viene de orígenes humildes para terminar como alcalde de Quito en el año 2019. En medio de esos dos puntos en una línea de tiempo pasa por una llamativa historia 
personal que lo lleva de médico cirujano, roquero romántico, locutor de radio, dueño de un conglomerado de medios de comunicación, presidente de un equipo de fútbol de primera división y asambleísta provincial. Principalmente a partir de sus inicios como locutor de radio, y posteriormente como dueño de un gran conglomerado de medios de comunicación, comienza a desplegar su talento como comunicador que le permite acumular un conocimiento y cercanía socio-cultural privilegiada sobre los sectores populares de la ciudad. En medio de una situación altamente inestable de las opciones electorales en la ciudad que toma fuerza a partir del año 2009 aparece la figura ascendente del outsider Yunda para ganar las elecciones para alcalde del año 2019. Su populismo se miró aquí como siendo más de estilo que de discurso polarizante, e ideológicamente se miró que es "ambiguo" e indefinido que de derecha o de izquierda.

Las encuestas previas a esa elección fueron poco acertadas para predecir el resultado final en donde el populismo con esas características de Yunda y el populismo más claramente de izquierda de la candidata "correísta" Luisa Maldonado terminaron sorpresivamente en los dos primeros lugares de esa elección. Allí se observó una clara distancia entre las élites políticas principales de la ciudad con amplios sectores medios y bajos de la ciudad. Aquella sorpresa se expresó en redes sociales en donde se mezcló la preocupación de sectores medios y altos sobre la idoneidad de Yunda para ocupar la alcaldía y la vigencia del correísmo en la política de la ciudad. También se desplegaron expresiones cargadas de racismo y clasismo frente a ese resultado lo cual muestra que la política quiteña está claramente determinada por la vigencia de clivajes jerárquicos socio-políticos heredados del periodo colonial del país, mezclados con la estructura de clases y las nuevas tecnologías comunicativas del capitalismo contemporáneo latinoamericano.

\section{BIBLIOGRAFÍA}

ALOMES, S., \& MASCITELLI, B. (2013). Celebrity meets Populism in Europe: The Political Performances of Nicolas Sarkozy and Silvio Berlusconi. Australian and New Zealand Journal of European Studies 2012(2) - 2013(1), 30-43.

BARR, R. R. (2017). The resurgence of populism in Latin America. Boulder: Lynne Rienner Publishers, Inc. https://doi.org/10.1111/tla.12138

BARTOSZEWICZ, M. G. (2019). Celebrity populism: a look at Poland and the Czech Republic. Recuperado el 13 de 08 de 2019, de European Politics and Society: article: https://doi.org/10.1080/23745118.2019.1569342

BASABE, S. (2016). Asociación cívica y desinstitucionalización de los partidos políticos en Ecuador: rupturas y continuidades, 1979-2014. Política y Sociedad Vol. 53, Núm. 3 , 937-960. https://doi.org/10.5209/rev_POSO.2016.v53.n3.49440

BENNETT, A., \& CHECKEL, J. T. (2015). Process tracing: from philosophical roots to best practices. En A. Bennett, \& J. T. Checkel (Edits.), Process tracing. From metaphor to analytic tool (págs. 3-37). Cambridge: Cambridge University Press. https://doi. org/10.1017/CBO9781139858472.003

BETZ, H.-G. (1994). Radical Right-Wing Populism in Western Europe. Londres: Macmillan. https://doi.org/10.1007/978-1-349-23547-6 
BRAUN, H. (1986). The Assassination of Gaitan. Public Life and Urban Violence in Colombia. Madison: University of Wisconsin Press.

Confirmado.net. (16 de 5 de 2019). Perfiles de Opinión: Gestión de Moreno cae al 24,18\%. Recuperado el 21 de 8 de 2019, de https://confirmado.net/2019/05/16/perfiles-deopinion-gestion-de-moreno-cae-al-2418/

COX, M. (2017). The Rise of Populism and the Crisis of Globalisation: Brexit, Trump and Beyond. Irish Studies in International Affairs, 1-9. https://doi.org/10.3318/ isia.2017.28.12

DE LA TORRE, C. (2013). El tecnopopulismo de Rafael Correa: ¿Es compatible el carisma con la tecnocracia? Latin American Research Review, Vol. 48, No. 1, 24-43.

DI TELLA, T. S. (1973). Populismo y reformismo. En G. Germani, T. S. di Tella, \& O. Ianni, Populismo y contradicciones de clase en Latinoamerica (págs. 38-81). México: Ediciones Era.

EL COMERCIO. (21 de 6 de 2009). Así está conformado el Conartel... Recuperado el 15 de 8 de 2019, de https://www.elcomercio.com/actualidad/conformado-conartel.html

EL UNIVERSO. (15 de 4 de 2019). Frecuencias y política marcan vida de Jorge Yunda. Recuperado el 21 de 8 de 2019, de https://www.eluniverso.com/noticias/2019/04/15/ nota/7286195/frecuencias-politica-marcan-vida-yunda

EL UNIVERSO. (1 de 12 de 2019). Proclaman candidatura de Jorge Yunda a la alcaldía de Quito. Recuperado el 21 de 8 de 2019, de https://www.eluniverso.com/ noticias/2018/12/01/nota/7077618/proclaman-candidatura-jorge-yunda-alcaldiaquito

FLACSO RADIO. (23 de 4 de 2019). Quito: los imaginarios del norte y del sur. Recuperado el 22 de 8 de 2019, de https://www.flacso.edu.ec/flacsoradio/quito-los-imaginariosdel-norte-y-del-sur

FREIDENBERG, F. (2014). Un país con mil reinos: Predominio de nuevos actores, estrategias políticas, e incongruencia multinivel en el Ecuador (1978-2014). En F. Freidenberg, \& J. Suárez-Cao, Territorio y poder. Nuevos actores y competencia política en los sistemas de partidos multinivel en América Latina (págs. 181-222). Ediciones Universidad de Salamanca.

GARCÍA AgUSTÍN, Ó., \& BRIZIARELli, M. (2018). Podemos and the New Political Cycle. Left-Wing Populism and Anti-Establishment Politics. Cham: Palgrave Macmillan. https://doi.org/10.1007/978-3-319-63432-6

GERMANI, G. (1973). Democracia representativa y clases populares. En G. Germani, T. S. di Tella, \& O. Ianni, Populismo y contradicciones de clase en América Latina (págs. 12-36). México: Ediciones Era.

HENTSCHKE, J. R. (2006). The Vargas Era Institutional and Development Model Revisited: Themes, Debates, and Lacunas. An Introduction. In J. R. Hentschke, Vargas and Brazil. New Perspectives (pp. 1-29). New York: Palgrave Macmillan. https://doi. org/10.1057/9780230601758_1

HERRERA SALAS, J. M. (2005). Ethnicity and Revolution. The Political Economy of Racism in Venezuela. Latin American Perspectives 141 Vol. 32 No. 2, March, 72-91.

JOHNSON III, O. A. (2012). Race, Politics, and Afro-Latin Americans. In P. Kingstone, \& D. J. Yashar, Routledge handbook of Latin American politics (pp. 302-317). New York and London: Routledge. 
LA HISTORIA. (10 de 4 de 2019). Yunda, de Guano con humor. Recuperado el 15 de 8 de 2019, de https://lahistoria.ec/2019/04/10/yunda-de-guano-con-humor/

LACLAU, E. (2004). La razón populista. Buenos Aires: Fondo de Cultura Económica.

LUCERO, J. A. (2017). Monuments of (de) colonization. Violence, democracy and gray zones in Bolivia after January 11, 2007. In S. E. Álvarez, J. W. Rubin, M. B. Thayer, \& A. Laó-Nontes, Beyond civil society. Activism, participation and protest in Latin America (pp. 296-314). Durham and London: Duke University Press.

MANUCCI, L. (11 de 2017). Populism and the Media. Recuperado el 13 de 08 de 2019, de Oxford Handbooks Online: 10.1093/oxfordhb/9780198803560.013.17

MAZZOLENI, G. (2008). Populism and the Media. En D. Albertazzi, \& D. McDonnell, Twenty-First Century Populism. The Spectre of Western European Democracy (págs. 49-65). New York: Palgrave. https://doi.org/10.1057/9780230592100_4

MOFFITT, B. (2018). The Populism/Anti-Populism Divide in Western Europe. Democratic Theory. Volume 5, Issue 2, Winter, 1-16. https://doi.org/10.3167/dt.2018.050202

MOUFFE, C. (2000). The democratic paradox. London and New York: Verso.

MUDDE, C. (2017). SYRIZA. The failure of the populist promise. Cham: Palgrave Macmillan. https://doi.org/10.1007/978-3-319-47479-3

MUDDE, C., \& ROVIRA KALTWASSER, C. (2017). Populism. A Very Short Introduction. Nueva York: Oxford University Press. https://doi.org/10.1093/ actrade/9780190234874.001.0001

NÁLliM, J. A. (2014). Las raices del anti-peronismo. Orígenes históricos e ideológicos. Buenos Aires: Capital intelectual.

OSTIGUY, P. (2017, 11). Populism: A Socio-Cultural Approach. Retrieved 10 16, 2018, from Oxford Handbooks Online: http://www.oxfordhandbooks.com/view/10.1093/ oxfordhb/9780198803560.001.0001/oxfordhb-9780198803560-e-3

PRIETO, M. (2004). Liberalismo y temor. Imaginando los sujetos indígenas en el Ecuador postcolonial. 1895-1950. Quito: FLACSO Ecuador y Abya Yala.

ROBERTS, K. M. (1995). Neoliberalism and the Transformation of Populism in Latin America: The Peruvian Case. World Politics, Vol. 48, No. 1, 82-116.

ROBERTS, K. M. (10 de 2017). Populism and Political Parties. Recuperado el 28 de 1 de 2019, de Oxford Handbooks Online: 10.1093/oxfordhb/9780198803560.013.20

ROJO, C., PRIETO, M., SANCHÍS, N., ROSERO, R., NORTH, L., \& VERDESOTO, L. (1984). 1984: Mujer y elecciones. Análisis del voto femenino en Quito. Quito: ILDIS.

RUZZA, C., \& BALBO, L. (2013). Italian Populism and the trajectory of two leaders: Silvio Berlusconi and Umberto Bossi. En R. Wodak, M. Khosravinik, \& B. Mral, RightWing Populism in Europe. Politics and discourse (págs. 163-175). Londres y Nueva York: Bloomsbury Academic.

SALAZAR MEDINA, R. (2 de 4 de 2019). Las lecciones y taras que dejaron los comicios. Recuperado el 22 de 8 de 2019, de El Telegrafo: https://www.eltelegrafo.com.ec/ noticias/politica/3/las-lecciones-y-taras-que-dejaron-los-comicios

STAVRAKAKIS, Y., KATSAMBEKIS, G., KIOUPKIOLIS, A., NIKISIANIS, N., \& SIOMOS, T. (2017). Populism, anti-populism and crisis. Contemporary Political Theory, 1-24. https://doi.org/10.1057/s41296-017-0142-y 
STAVRAKAKIS, Y., KIOUPKIOLIS, A., KATSAMBEKIS, G., NIKISIANIS, N., \& SIOMOS, T. (2016). Contemporary Left-wing Populism in Latin America: Leadership, Horizontalism, and Postdemocracy in Chávez's Venezuela. Latin American Politics and Society Volume 58, Issue 3 Fall , 51-76. https://doi. org/10.1111/j.1548-2456.2016.00318.x

UNDA, M. (2019). Quito en elecciones -El sello social del voto. Sociología y Politica HOY. Red de Carreras de Sociología y Ciencias Políticas del Ecuador. No. 1, junio-julio, 35-42.

VAN DYCK, B. (2019). Why Not Anti-Populist Parties? Theory with Evidence from the Andes and Thailand. Comparative politics Volume 51, Number 3, April, 361-383. https://doi.org/10.5129/001041519X15647434970009

VÁSQUEZ, P. (2017). El programa radial "El Apagón”, historia y recepción. Caso: barrio La Vicentina - Quito Ecuador 2015. Quito: Universidad Andina Simón BolívarSede Ecuador-Tesis de Maestría en Comunicación.

VISTAZO. (25 de 3 de 2019). ¿Quién es Jorge Yunda? Recuperado el 15 de 8 de 2019, de https:/www.vistazo.com/seccion/elecciones-2019/pais/quien-es-jorge-yunda

WEYLAND, K. (1999). Neoliberal Populism in Latin America and Eastern Europe. Comparative Politics, Vol. 31, No. 4 (Jul., 1999), 379-401. https://doi. org/10.2307/422236

WEYLAND, K. (2013). The threat from the populist left. Journal of Democracy, Volume 24, Number 3, 18-32. https://doi.org/10.1353/jod.2013.0045

WOODARD, J. P. (2006). "All for São Paulo, All for Brazil": Vargas, the Paulistas, and the Historiography of Twentieth-Century Brazil. In J. R. Hentschke, Vargas and Brazil. New Perspectives (pp. 83-108). New York: Palgrave Macmillan. https://doi. org/10.1057/9780230601758 
